\title{
Circulating resistin levels are early and significantly increased in deceased brain dead organ donors, correlate with inflammatory cytokine response and remain unaffected by steroid treatment
}

\author{
Rille Pullerits ${ }^{1,2}$, Simona Oltean ${ }^{1}$, Anne Flodén ${ }^{3}$ and Mihai Oltean ${ }^{4,5^{*}}$
}

\begin{abstract}
Introduction: Resistin is a pro-inflammatory adipokine that increases after brain injury (trauma, bleeding) and may initiate an inflammatory response. Resistin was found increased in deceased, brain dead organ donors (DBD) and correlated with delayed graft function after kidney transplantation. The kinetics of resistin during brain death (BD), its impact on the inflammatory response and the influence of several donor variables on resistin levels are still unknown.

Methods: Resistin along with a panel of Th1/Th2 cytokines [interferon (IFN)-gamma, interleukin (IL)-1 beta, IL-2, IL-6, IL-8, IL 10, IL-12, IL-13 and tumor necrosis factor (TNF)] was analyzed in 36 DBDs after the diagnosis of BD and before organ procurement and in 12 living kidney donors (LD). The cytokine levels and resistin were analyzed in relation to donor parameters including cause of death, donors' age and steroid treatment.

Results: Resistin levels were higher in DBDs both at BD diagnosis and before organ procurement compared to LD $(p<0.001)$. DBDs had significantly increased IL-1 beta, IL-6, IL-8, IL-10 and TNF levels at both time points compared with LD. In DBDs, resistin at BD diagnosis correlated positively with IL-1 beta $\left(r_{s} 0.468, P=0.007\right), I L-6\left(r_{s} 0.511\right.$, $p=0.002), I L-10\left(r_{s} 0.372, p=0.028\right), I L-12\left(r_{s} 0.398, p=0.024\right), I L-13\left(r_{s} 0.397, p=0.030\right)$ and TNF $\left(r_{s} 0.427, p=0.011\right)$ at procurement. The cause of death, age over 60 and steroid treatment during BD did not affect resistin levels. However, steroid treatment significantly decreased pro-inflammatory cytokines IL-1 beta, IL-8, TNF and IFN-gamma at the time of organ procurement.

Conclusions: Resistin is increased early in DBDs, remains increased throughout the period of BD and correlates strongly with pro-inflammatory mediators. Resistin level, in contrast to cytokines, is not affected by steroid treatment. Resistin increase is related to the BD but is not influenced by age or cause of death. Resistin may be one of the initial triggers for the systemic inflammatory activation seen in DBDs.
\end{abstract}

Keywords: Resistin, Brain death, Organ donor, Cytokines, Steroid treatment

\section{Background}

Deceased brain dead (DBD) organ donors regularly manifest a pronounced inflammatory state resembling

\footnotetext{
*Correspondence: mihai.oltean@surgery.gu.se

${ }^{4}$ The Transplant Institute, Sahlgrenska University Hospital,

41345 Gothenburg, Sweden

Full list of author information is available at the end of the article
}

the systemic inflammatory response syndrome (SIRS) but its initiating stimuli still remain incompletely known. The increased circulating pro-inflammatory mediators (cytokines, chemokines) released before or during the period between the declaration of brain death and organ procurement lead to an increased apoptosis, inflammatory activation and tissue injury in various organs $[1$, 2]. These changes increase the susceptibility for both 
ischemia-reperfusion injury as well as rejection, and may contribute to the inferior results recorded following transplantation of organs from deceased donors as compared with those obtained from healthy, living donors [3, $4]$.

Resistin, a protein initially described as an adipocytesecreted peptide in rodents and postulated to contribute to insulin resistance, has recently been shown to play an important role in the various inflammatory conditions [5]. In humans, resistin expression on primary adipocytes is low whereas it is highly expressed on the cells of monocyte-macrophage lineage $[5,6]$. Resistin has several features in common with pro-inflammatory cytokines $[7,8]$. It promotes inflammation through induction of other cytokines and the expression of resistin itself is strongly up-regulated on the peripheral blood mononuclear cells in response to stimulation with pro-inflammatory cytokines such as IL- 6 , TNF- $\alpha$ and IL- $1 \beta$ and LPS $[7,9]$. In humans, elevated levels of resistin are frequently found in association with autoimmune diseases and inflammation [5]. Resistin has been implicated in obesity, diabetes, and atherosclerosis, cardiovascular and rheumatic diseases [10-13]. Increased resistin levels have also been reported in patients with intracerebral hemorrhage and head trauma [14, 15]. Importantly, we recently showed that increased resistin level measured in brain dead organ donors was associated with delayed graft function and need for dialysis in kidney allograft recipients after transplantation of kidneys from these donors [16]. However, it is unclear whether higher resistin concentrations are present already at the time of diagnosis of brain death and whether resistin further increases during the period between the declaration of BD and organ procurement. Since resistin is able to initiate endothelial activation [17], and induce a pro-inflammatory cytokine response [7], it could commence and further amplify the systemic inflammatory response syndrome and serve as a potential target of the therapy. Therefore, it is imperative to understand the underlying mechanisms and identify therapeutic interventions that may curb the development of the systemic inflammation in the DBD and limit its consequences on the transplantable organs.

Here, we studied the kinetics of resistin in DBD organ donors between the declaration of brain death and organ procurement, the relationship of resistin with cytokines, donor characteristics and pharmacologic interventions in the donor.

\section{Methods}

\section{Patients and samples}

Plasma samples were obtained from 36 DBD organ donors from our procurement area between December 2011 and March 2014. The donors (or next of kin) previously had consented for blood/tissue donation for the purpose of medical research. The study was approved by the Ethical Committee of the University of Gothenburg.

Blood was drawn in ethylene-diamine-tetra-acetic acid (EDTA) containing tubes from DBD donors on the intensive care unit at the time of diagnosis of brain death (acceptance as organ donors) and in the operation room immediately before the start of the organ procurement procedure. The blood was stored at $4^{\circ} \mathrm{C}$ until centrifugation. Following centrifugation at $2000 \mathrm{rpm}$ for $5 \mathrm{~min}$ plasma was recovered, aliquoted and stored at $-80^{\circ} \mathrm{C}$ until analysis. Donor information regarding age, gender and cause of death were retrieved. Methylprednisolone was given to all donors considered for thoracic organ procurement soon after the declaration of brain death and acceptance into donorship $(15 \mathrm{mg} / \mathrm{kg})$.

Blood samples were also obtained from healthy individuals donating a kidney for transplantation at our unit (i.e. living donors, LD) the day before surgery. All LD were informed and consented for the sampling and the samples were prepared as described above.

\section{Measurement of resistin and cytokines}

Resistin was measured using a colorimetric sandwich ELISA kit (RnD Systems, Minneapolis, MN, USA) following manufacturer's instructions. The lower detection limit was $0.16 \mathrm{ng} / \mathrm{ml}$ for resistin. The samples also were analyzed for a panel of pro-inflammatory (Th1) and antiinflammatory (Th2) cytokines. Plasma concentrations of IFN- $\gamma$, IL-1 $\beta$, IL-2, IL-4, IL-6, IL-8, IL-10, IL-12p70, IL-13 and TNF were determined by the electro-chemiluminescence multiplex system Sector 2400 imager from Meso Scale Discovery (Gaithersburg, MD, USA).

\section{Statistical analyses}

Non-parametric statistical methods were used since all continuous variables from DBD as tested for Gaussian distribution with D'Agostino and Pearson omnibus normality test showed non-normal distribution. KruskalWallis test followed by Dunn's multiple comparisons correction test was used to compare the mean rank values if three or more groups were analysed. Statistically significant relationships were further analyzed using the Mann-Whitney U test. The Wilcoxon signed rank test for paired samples was used to analyze the changes in variables between two time points. Associations between variables were assessed using the Spearman's rank correlation test and coefficient expressed as Spearman's rho. Analyses were performed using GraphPad Prism v. 6 (GraphPad software). Data are expressed as median and range, unless otherwise stated. A $p$ value $<0.05$ was considered significant. 


\section{Results}

\section{Donor characteristics}

Samples were obtained from 36 DBD donors and 12 living donors. DBD donors were significantly older than LD [median age 64 (range 7-79) vs 46 (34-66), respectively]. Table 1 summarizes the main donor characteristics.

\section{Resistin levels in the deceased brain dead and living donors}

Median resistin concentration in the LD group was $8 \mathrm{ng} /$ $\mathrm{ml}$ (range 4-12 $\mathrm{ng} / \mathrm{ml}$ ). In DBD donors, resistin was found at 4-5-fold higher concentrations than in LD at both time-points ( $\mathrm{p}<0.0001)$. Median resistin concentration at the time of diagnosis of $\mathrm{BD}$ and acceptance to the donorship was $41(13-120) \mathrm{ng} / \mathrm{ml}$, while its median concentration immediately before procurement was 39 (9-117) (Figure 1a). No significant differences were observed regarding resistin levels when the DBD donors were stratified according to the cause of brain death (Figure 1b). At the diagnosis of BD, the median resistin concentrations in donors with cerebrovascular bleeding,

Table 1 Donor characteristics $(n=36)$

\begin{tabular}{ll}
\hline Deceased donors & \\
Male/Female & $20 / 16$ \\
Age (median, range) & $64(7-79)$ \\
Cause of death (\%) & \\
$\quad$ Cerebrovascular accident & $18(50 \%)$ \\
Anoxia & $12(33 \%)$ \\
Trauma & $6(17 \%)$ \\
Steroid treatment (\%) & $21(58 \%)$ \\
Time between samplings (min) & $352(120-1,200)$ \\
Living donors ( $n=12)$ & \\
Male/Female & $3 / 9$ \\
Age (median, range) & $46(34-66)$ \\
\hline
\end{tabular}

anoxia and trauma were 36 (13-120) ng/ml, 44 (19-102) $\mathrm{ng} / \mathrm{ml}$ and $41(14-80) \mathrm{ng} / \mathrm{ml}$, respectively.

\section{The cytokine levels in the deceased brain dead and living donors}

Serum concentrations of IL-6 and IL-10 were significantly higher in DBD donors compared to LD at the time of brain death diagnosis [IL-6: $152(4-2,513) \mathrm{ng} / \mathrm{ml}$ vs 0.6 (0.3-5.3) ng/ml, $\mathrm{p}=0.0001$; IL-10: 2.4 (0.3-46.6) ng/ml vs $0.2(0.1-0.4) \mathrm{ng} / \mathrm{ml}, \mathrm{p}=0.004$, respectively]. At the organ procurement, IL-6 and IL-10 levels in DBD were $91(3-2,760) \mathrm{ng} / \mathrm{ml}$ and $1.8(0.3-31) \mathrm{ng} / \mathrm{ml}$, respectively. The level of IL-2, IL-8, IL-12, IL-13, and TNF were significantly higher in DBDs at the time of brain death diagnosis as compared to LD.

During the period of brain death, IFN- $\gamma$, IL-1 $\beta$, IL-2, IL- 8 and TNF significantly decreased and lower values were detected immediately before the organ procurement (T2) compared with the values at the declaration of $\mathrm{BD}$ (T1). The concentration of the various Th1 and Th2 cytokines are summarized in Figures 2 and 3.

Overall, the cytokine levels were elevated more than 2 standard deviations above the mean level of that detected in LD in the majority of DBD. IFN- $\gamma$ was elevated in $29 \%$, IL-2 in $36 \%$, IL-12 in $47 \%$, IL-13 in $56 \%$, IL-1 $\beta$ in $60 \%$, IL- $874 \%$, TNF in $86 \%$, IL-10 in $94 \%$ and IL- 6 in $100 \%$ of DBD donors. At organ procurement, $97 \%$ of DBD donors had high IL-6 and IL-10 levels in relation to LD, and elevated TNF was seen in 77\% (Figures 2, 3).

\section{The relationship between resistin and cytokines}

At the time of $\mathrm{BD}$ diagnosis, a positive association was found between resistin and IL-1 $\beta$, IL-2, IL-6, IL-12 and IL-13 levels. Resistin levels measured at the BD diagnosis correlated strongly with IL-6 $\left(\mathrm{r}_{\mathrm{s}} 0.511, \mathrm{p}=0.002\right)$, TNF $\left(\mathrm{r}_{\mathrm{s}}\right.$ 0.427, $\left.\mathrm{p}=0.011\right)$, IL-1 $\beta\left(\mathrm{r}_{\mathrm{s}} 0.468, \mathrm{p}=0.007\right)$ and $\bmod -$ erately with IL-10 $\left(\mathrm{r}_{\mathrm{s}} 0.372, \mathrm{p}=0.028\right), \mathrm{IL}-12\left(\mathrm{r}_{\mathrm{s}} 0.398\right.$,
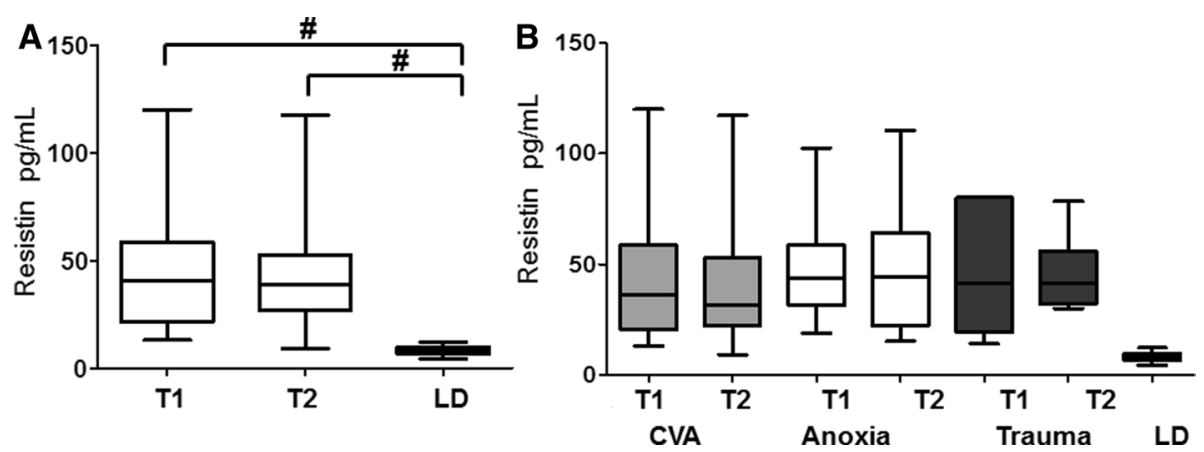

Figure 1 a Resistin levels in all the DBD donors at the time of the diagnosis of brain death ( $T 1$ ), immediately before organ procurement (T2) and in living kidney donors (LD). b Resistin levels at both timepoints in DBD donors divided according to the cause of death. The box plots show medians and interquartile range, whiskers show 5-95th percentiles; ${ }^{*} \mathrm{p}<0.001 ;$ CVA cerebrovascular accident. 


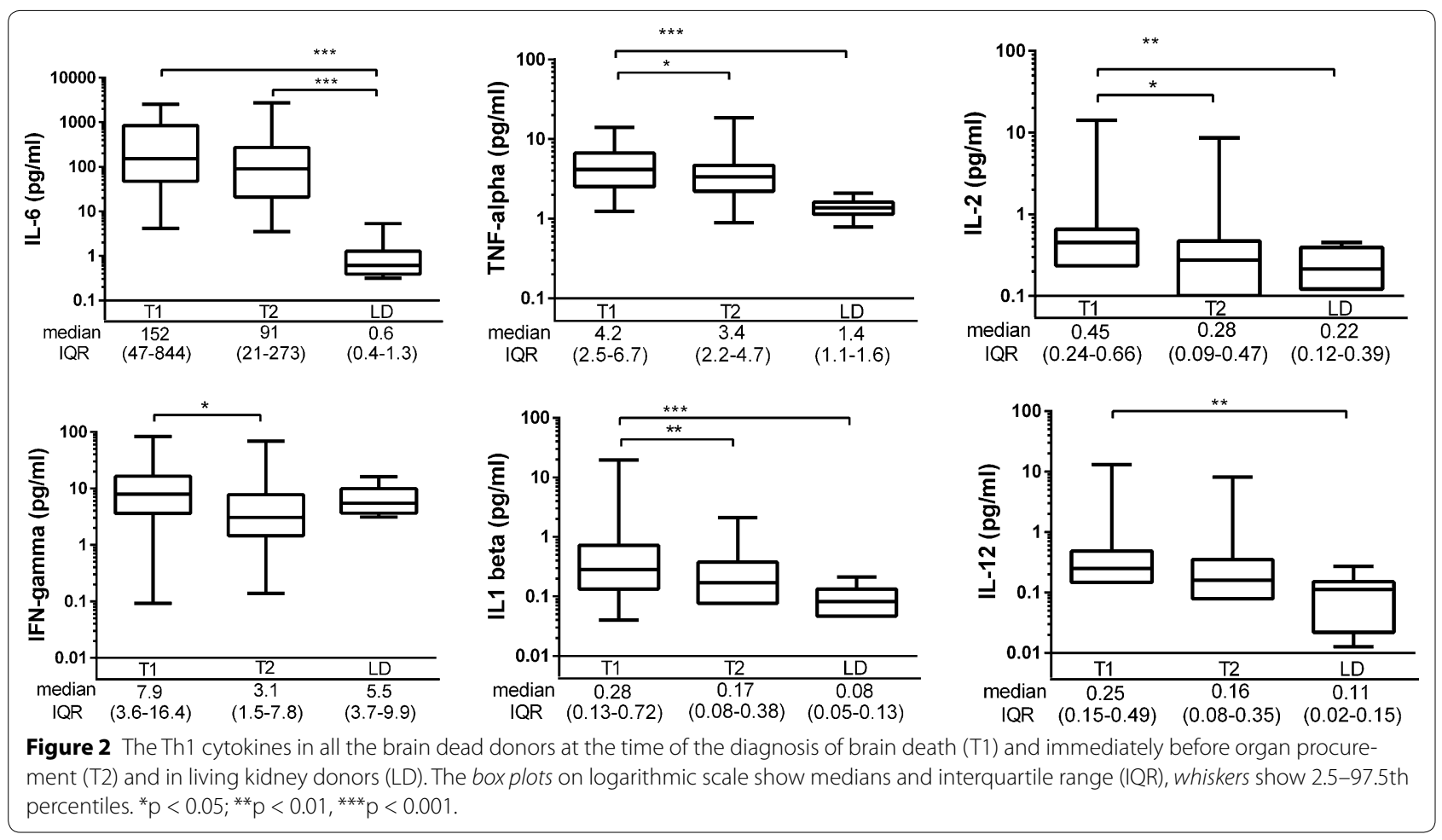

$\mathrm{p}=0.024)$, and IL-13 $\left(\mathrm{r}_{\mathrm{s}} 0.397, \mathrm{p}=0.03\right)$ at the time of procurement (Table 2).

\section{The effect of steroid treatment on resistin and cytokine levels}

The median resistin levels did not differ between DBD donors receiving methylprednisolone treatment $(\mathrm{n}=24)$ or non-treated DBD donors $(\mathrm{n}=12)$ at any time-point. However, methylprednisolone administration during the period between the diagnosis of brain death and organ procurement resulted in lower concentrations of donor IFN- $\gamma$, IL-1 $\beta$, IL- 8 and TNF at the time of organ procurement as compared to the levels at diagnosis. Of note, the levels of IFN- $\gamma$, TNF and IL- $1 \beta$ were significantly lower in steroid treated BDB donors as compared to the levels in the non-treated DBD donors at the time of organ procurement (Figure 4). Also, IL-6 concentrations were significantly lower in steroid treated DBD donors at the time of organ procurement $(\mathrm{p}<0.05)$ and a trend towards the decrease of IL- 6 levels between two time points was seen following steroid treatment $(\mathrm{p}=0.09)$ (Figure 5).

Importantly, the resistin concentration at $\mathrm{BD}$ diagnosis correlated strongly with IL-1 $\beta\left(\mathrm{r}_{\mathrm{s}} 0.672, \mathrm{p}=0.023\right)$, IL-2 $\left(r_{\mathrm{s}} 0.700 \mathrm{p}=0.016\right)$, IL-6 $\left(\mathrm{r}_{\mathrm{s}} 0.726, \mathrm{p}=0.011\right)$ and IL-12 $\left(\mathrm{r}_{\mathrm{s}}, 0.697, \mathrm{p}=0.025\right)$ at organ procurement in the DBD donors that did not receive steroid treatment.
Older donors $(>60)$ did not differ at any of the two time points from the younger donors with respect to resistin levels and the studied cytokines.

\section{Discussion}

We recently reported increased resistin at the time of organ procurement but it has been unclear whether this increase occurred in the time elapsed between $\mathrm{BD}$ diagnosis and organ donation or this increase was apparent at an earlier moment. The current results indicate an increased plasma resistin and a robust cytokine response already very early in the process of organ donation.

Increased resistin concentration has been detected after the head trauma or intracerebral bleeding and it has been suggested that its concentration is proportional with the magnitude of injury $[15,18]$. This increase is quite rapid and significant since resistin increase may occur in head trauma setting within $6 \mathrm{~h} \mathrm{[14].} \mathrm{We} \mathrm{found}$ similar concentrations of resistin as those reported earlier after severe head trauma or intracerebral bleeding. However, during a median observation period range of 2-20 h during the BD we did not observe any further increase suggesting that resistin increase is not a phenomenon specific for the state of brain death but rather of the brain injury leading to the $\mathrm{BD}$, independently of the mechanism of injury. 

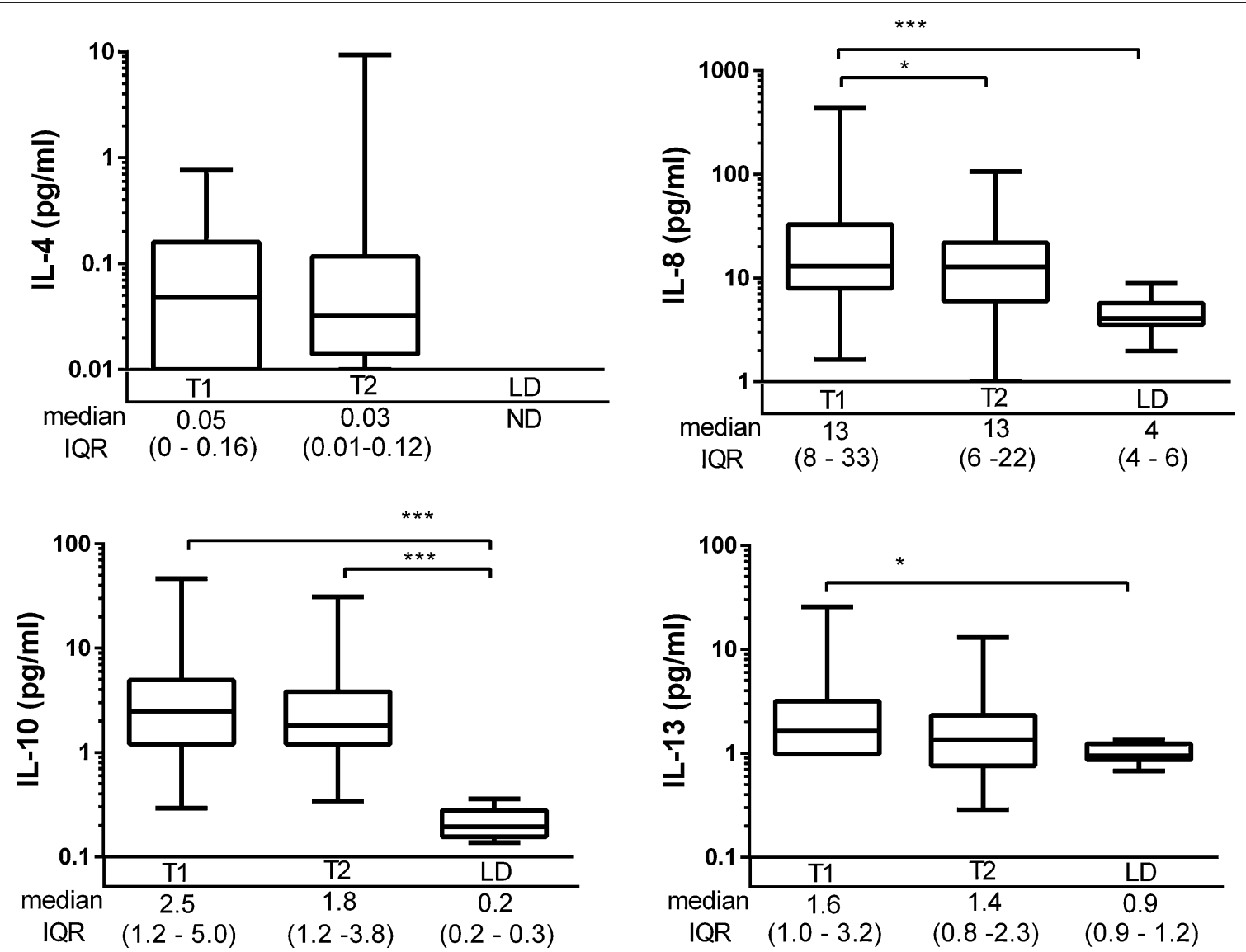

Figure 3 The Th2 cytokines in all the brain dead donors at the time of the diagnosis of brain death (T1) and immediately before organ procurement (T2) and in living kidney donors (LD). The boxplots on logarithmic scale show medians and interquartile range (IQR), whiskers show 2.5-97.5th percentiles. ${ }^{*} p<0.05 ;{ }^{* * *} p<0.001$.

Table 2 Resistin level at the diagnosis of brain death is associated with cytokines at the diagnosis of brain death (T1) and at organ procurement (T2)

\begin{tabular}{|c|c|c|c|c|c|c|}
\hline \multirow[t]{2}{*}{ Cytokine } & \multicolumn{2}{|c|}{ T1 all donors $(n=36)$} & \multicolumn{2}{|c|}{ T2 all donors $(n=36)$} & \multicolumn{2}{|c|}{ T2 untreated donors $(n=12)$} \\
\hline & $r_{s}$ & P value & $r_{s}$ & $P$ value & $r_{s}$ & $p$ value \\
\hline IFN-gamma & 0.034 & 0.847 & 0.207 & 0.234 & 0.500 & 0.117 \\
\hline IL-1 beta & 0.431 & 0.010 & 0.468 & 0.007 & 0.673 & 0.023 \\
\hline$\| \mathrm{L}-2$ & 0.350 & 0.046 & 0.248 & 0.178 & 0.700 & 0.016 \\
\hline $\mid \mathrm{L}-4$ & 0.129 & 0.505 & 0.318 & 0.114 & 0.667 & 0.049 \\
\hline IL-6 & 0.398 & 0.018 & 0.511 & 0.002 & 0.727 & 0.011 \\
\hline IL-8 & 0.314 & 0.066 & 0.116 & 0.509 & 0.082 & 0.81 \\
\hline $\mathrm{IL}-10$ & 0.217 & 0.210 & 0.372 & 0.028 & 0.318 & 0.340 \\
\hline $\mid \mathrm{L}-12$ & 0.444 & 0.009 & 0.398 & 0.024 & 0.697 & 0.025 \\
\hline IL-13 & 0.503 & 0.003 & 0.397 & 0.030 & 0.482 & 0.133 \\
\hline TNF & 0.249 & 0.149 & 0.427 & 0.011 & 0.455 & 0.160 \\
\hline
\end{tabular}

The associations were assessed with two-tailed Spearman's rank correlation test and the correlation coefficient $\left(r_{s}\right)$ and $p$ value are shown.

Accumulating evidence supports a role of human resistin as a pro-inflammatory molecule. Human resistin is highly expressed, up-regulated and secreted from peripheral blood mononuclear cells (PBMC), macrophages and neutrophils in response to various stimuli $[6,9,19]$, and in turn, acts on these cells and leads to enhanced inflammatory reaction 


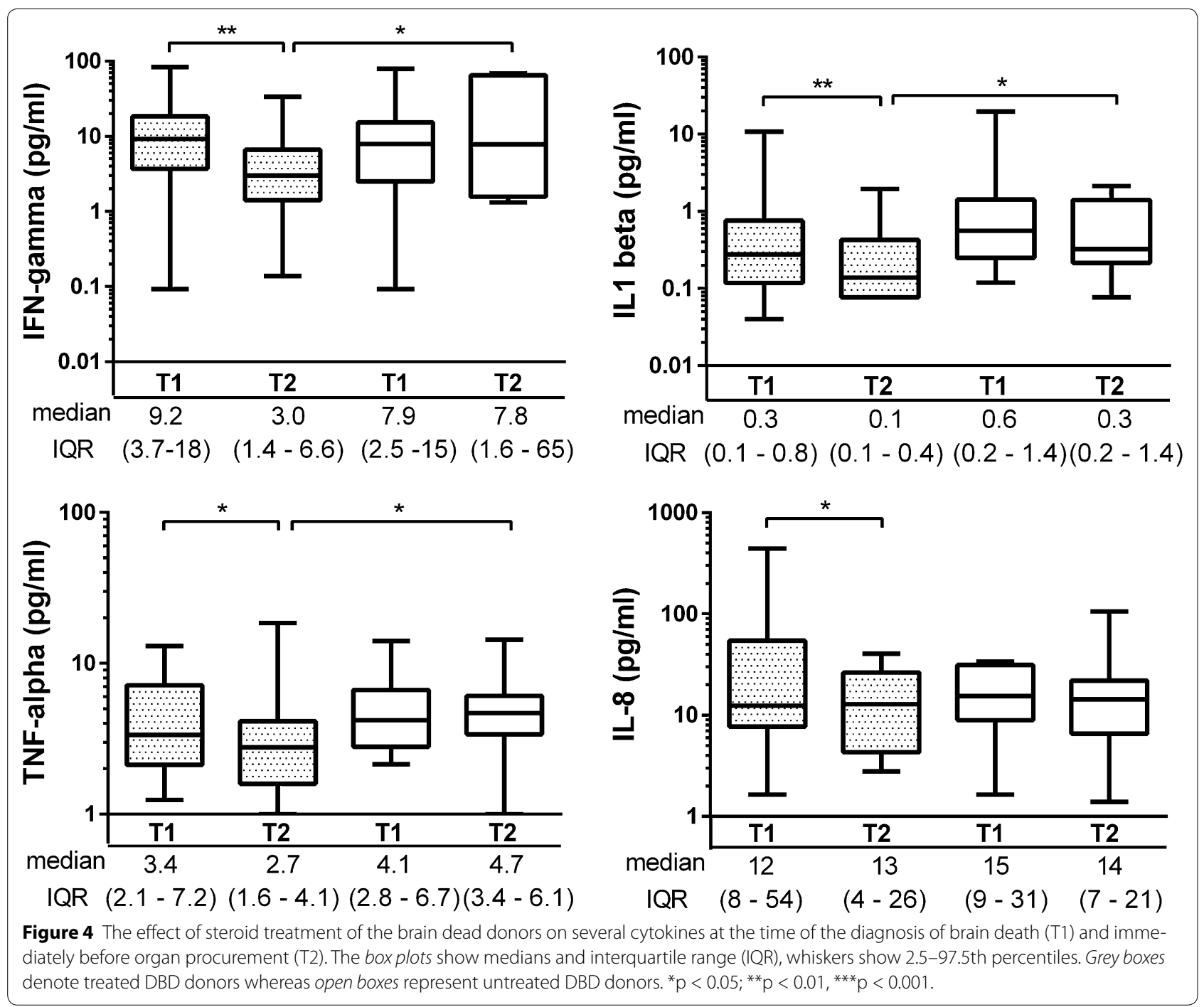

through activation of intracellular signaling [20]. Although the receptor for resistin is still disputed [21, 22] it is shown that the subsequent intracellular signaling occurs mainly through the NF- $\kappa \mathrm{B}$ pathway, the same pro-inflammatory pathway involved in the synthesis and secretion of numerous pro-inflammatory cytokines shifting cells towards an inflammatory phenotype $[17,20,23]$. Resistin has been shown to up-regulate the expression of TNF, IL-6, IL-12 in PBMC and macrophages $[7,20]$. In line with these findings, we identified strong positive correlations between the resistin levels at the diagnosis of brain death and several major pro-inflammatory cytokines at both the first and the second time-point during the brain death. The correlation between resistin and TNF, IL-1 $\beta$ and IL- 6 were stronger at the latter time-point before organ procurement.

The current results may infer a causal relationship between resistin and these cytokines and indirectly suggest resistin as an initial stimulus for inflammatory status of DBDs but more work at molecular level on clinical samples is needed in order to establish its significance and biological effects. In this setting rodent models of $\mathrm{BD}$ may have a limited value as the biologic roles of resistin differ between rodents and humans and rodent models tend to have a shorter duration and more limited possibilities for therapeutic interventions.

The induction of a cytokine response during BD and the inflammatory activation of various organs have earlier been reported both in experimental and clinical setting [1, 24]. This systemic inflammatory response ultimately results in an inflammatory cascade including complement activation, endothelial activation and increased pro-inflammatory mediators. All these molecular events cause direct injury to the various transplantable organs, increase the susceptibility of the future graft to ischemia-reperfusion injury and may ultimately relate with increased recipient mortality after transplantation 


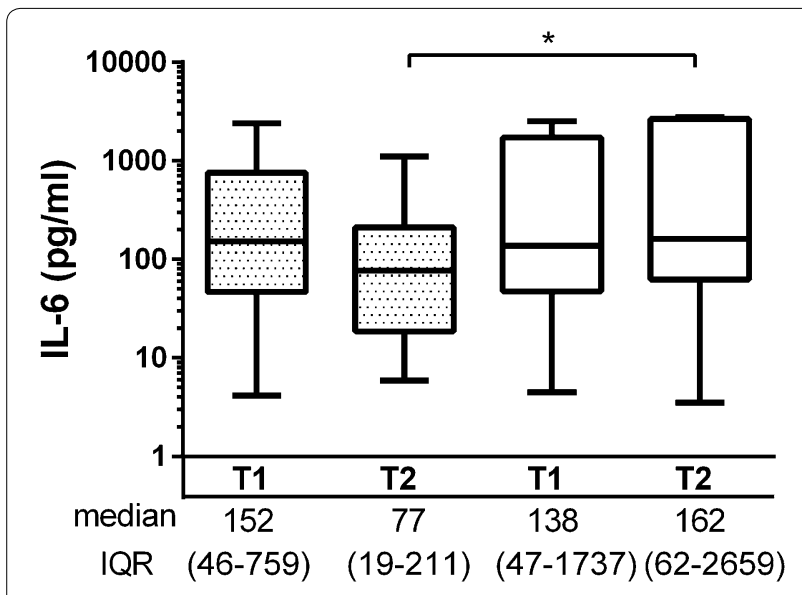

Figure $\mathbf{5}$ The effect of steroid treatment of the brain dead donors on interleukin- 6 at the time of the diagnosis of brain death (T1) and immediately before organ procurement (T2). The box plots on logarithmic scale show medians and interquartile range (IQR), whiskers show 2.5-97.5th percentiles. Grey boxes denote treated DBD donors whereas open boxes represent untreated DBD donors. * $p<0.05$; ${ }^{* *} \mathrm{p}<0.01,{ }^{* * *} \mathrm{p}<0.001$

[25]. Steroid treatment has been shown to abate the levels of several pro-inflammatory factors both in the tissue and in the circulation and may improve the outcome of transplantation [26, 27]. In line with these studies, we found lower levels of pro-inflammatory cytokines at the latter time-point in the DBDs treated with steroids. This suggests that in spite of high levels of resistin still present in circulation, part of its pro-inflammatory effects may be alleviated by steroids.

The present report is from a single-center and has the characteristic limitations of any small series in which the low number and the heterogeneity of the donors prevented further in-depth subgroup analyses and could have made some results prone to a type 2 error. The lack of information on the inflammatory response in the tissues of the various transplantable organs somewhat restricts the interpretation of the data. According to our centers' policy, biopsies are taken only after graft reperfusion and hence, no tissues from earlier time-points were available for further analyses.

A significant strength is the collection of data from two time-points, allowing for certain mechanistic studies. Moreover, we avoided the confounding influence of the surgical stress on the cytokine response by performing the last sampling before the start of the organ procurement procedure [28]. Although the DBDs studied herein were not consecutive and included only donors who previously consented for the research purposes, the studied group mirrors well the overall donor characteristics at our center with regard to age, gender and cause of death. Our single center study also has the advantage of managing both organ donors and transplant recipients according to similar protocols and routines throughout the study.

\section{Conclusion}

Our results indicate that high resistin levels were detected already early in DBD in the process of organ donation. Resistin levels remained increased throughout the period of brain death and correlated strongly with several major pro-inflammatory circulating mediators. Resistin level, in contrast to cytokines, was not affected by steroid treatment. Our observations propose resistin as an early potential stimulus for the systemic inflammatory response seen during brain death and confirm the ability of methylprednisolone treatment to down-regulate key pro-inflammatory cytokines in DBDs.

\section{Key messages}

- Deceased brain dead donors have greatly increased circulating resistin already at the time of diagnosis of brain death.

- Early resistin levels correlate strongly with several Th1 cytokines immediately before organ procurement.

- Donor treatment with steroids alleviate the cytokine response in spite of high resistin levels.

\section{Abbreviations}

BD: brain death; COD: cause of death; DBD: deceased brain dead donor; ECD: expanded criteria donor; EDTA: ethylenediaminetetraacetic acid; IL: interleukin; IFN: interferon; LD: living donor.

\section{Authors' contributions}

RP carried out analyses, wrote and reviewed the manuscript; SO analyzed data, wrote and reviewed the manuscript; AF designed the study, collected data, reviewed the manuscript; $M O$ designed the study, analyzed data, drafted and reviewed the manuscript. All authors read and approved the final manuscript.

\section{Author details}

1 Department of Clinical Immunology and Transfusion Medicine, Sahlgrenska University Hospital, Gothenburg, Sweden. ${ }^{2}$ Department of Rheumatology and Inflammation Research, Institute of Medicine, The Sahlgrenska Academy at University of Gothenburg, Gothenburg, Sweden. ${ }^{3}$ Organ Donation Unit, Sahlgrenska University Hospital, Gothenburg, Sweden. ${ }^{4}$ The Transplant Institute, Sahlgrenska University Hospital, 41345 Gothenburg, Sweden. ${ }^{5}$ Department of Surgery, Institute of Clinical Sciences, The Sahlgrenska Academy at University of Gothenburg, Gothenburg, Sweden.

\section{Acknowledgements}

The study was supported by funds from Gelin Memorial Foundation for Transplantation Research, Lennart Jacobssons testamentary stipendium for kidney transplantation research and Sahlgrenska University Hospital.

\section{Compliance with ethical guidelines}

\section{Competing interests}

The authors declare that they have no competing interests.

Received: 6 February 2015 Accepted: 16 June 2015

Published online: 26 June 2015 


\section{References}

1. Nijboer WN, Schuurs TA, van der Hoeven JA, Fekken S, Wiersema-Buist J, Leuvenink HG et al (2004) Effect of brain death on gene expression and tissue activation in human donor kidneys. Transplantation 78:978-986

2. Van Der Hoeven JA, Moshage H, Schuurs T, Nijboer M, Van Schilfgaarde R, Ploeg RJ (2003) Brain death induces apoptosis in donor liver of the rat. Transplantation 76:1150-1154

3. Weiss S, Kotsch K, Francuski M, Reutzel-Selke A, Mantouvalou L, Klemz R et al (2007) Brain death activates donor organs and is associated with a worse I/R injury after liver transplantation. Am J Transplant 7:1584-1593

4. Dziodzio T, Biebl M, Pratschke J (2014) Impact of brain death on ischemia/ reperfusion injury in liver transplantation. Curr Opin Organ Transplant 19:108-114

5. Filkova M, Haluzik M, Gay S, Senolt L (2009) The role of resistin as a regulator of inflammation: implications for various human pathologies. Clin Immunol 133:157-170

6. Patel L, Buckels AC, Kinghorn IJ, Murdock PR, Holbrook JD, Plumpton C et al (2003) Resistin is expressed in human macrophages and directly regulated by PPAR gamma activators. Biochem Biophys Res Commun 300:472-476

7. Bokarewa M, Nagaev I, Dahlberg L, Smith U, Tarkowski A (2005) Resistin, an adipokine with potent proinflammatory properties. J Immunol 174:5789-5795

8. Tilg H, Moschen AR (2006) Adipocytokines: mediators linking adipose tissue, inflammation and immunity. Nat Rev Immunol 6:772-783

9. Kaser S, Kaser A, Sandhofer A, Ebenbichler CF, Tilg H, Patsch JR (2003) Resistin messenger-RNA expression is increased by proinflammatory cytokines in vitro. Biochem Biophys Res Commun 309:286-290

10. Ding Q, White SP, Ling C, Zhou W (2011) Resistin and cardiovascular disease. Trends Cardiovasc Med 21:20-27

11. Gomez-Ambrosi J, Fruhbeck G (2005) Evidence for the involvement of resistin in inflammation and cardiovascular disease. Curr Diabetes Rev 1:227-234

12. Nasr R, Reed AM, Peterson EJ (2012) Update: biomarkers for idiopathic inflammatory myopathies. Curr Opin Rheumatol 24:609-615

13. Krysiak R, Handzlik-Orlik G, Okopien B (2012) The role of adipokines in connective tissue diseases. Eur J Nutr 51:513-528

14. Dong XQ, Yang SB, Zhu FL, Lv QW, Zhang GH, Huang HB (2010) Resistin is associated with mortality in patients with traumatic brain injury. Crit Care 14:R190

15. Dong $X Q, H u Y Y, Y u W H$, Zhang ZY (2010) High concentrations of resistin in the peripheral blood of patients with acute basal ganglia hemorrhage are associated with poor outcome. J Crit Care 25:243-247

16. Oltean S, Pullerits R, Floden A, Olausson M, Oltean M (2013) Increased resistin in brain dead organ donors is associated with delayed graft function after kidney transplantation. J Transl Med 11:233

17. Verma S, Li SH, Wang CH, Fedak PW, Li RK, Weisel RD et al (2003) Resistin promotes endothelial cell activation: further evidence of adipokineendothelial interaction. Circulation 108:736-740
18. Efstathiou SP, Tsiakou AG, Tsioulos DI, Panagiotou TN, Pefanis AV, Achimastos AD et al (2007) Prognostic significance of plasma resistin levels in patients with atherothrombotic ischemic stroke. Clin Chim Acta 378:78-85

19. Bostrom EA, Tarkowski A, Bokarewa M (2009) Resistin is stored in neutrophil granules being released upon challenge with inflammatory stimuli. Biochim Biophys Acta 1793:1894-1900

20. Silswal N, Singh AK, Aruna B, Mukhopadhyay S, Ghosh S, Ehtesham NZ (2005) Human resistin stimulates the pro-inflammatory cytokines TNFalpha and IL-12 in macrophages by NF-kappaB-dependent pathway. Biochem Biophys Res Commun 334:1092-1101

21. Tarkowski A, Bjersing J, Shestakov A, Bokarewa MI (2010) Resistin competes with lipopolysaccharide for binding to toll-like receptor 4. J Cell Mol Med 14:1419-1431

22. Lee S, Lee HC, Kwon YW, Lee SE, Cho Y, Kim J et al (2014) Adenylyl cyclaseassociated protein 1 is a receptor for human resistin and mediates inflammatory actions of human monocytes. Cell Metab 19:484-497

23. Zhang J, Lei T, Chen X, Peng Y, Long H, Zhou L et al (2010) Resistin upregulates COX-2 expression via TAK1-IKK-NF-kappaB signaling pathway. Inflammation 33:25-33

24. Pratschke J, Kofla G, Wilhelm MJ, Vergopoulos A, Laskowski I, Shaw GD et al (2001) Improvements in early behavior of rat kidney allografts after treatment of the brain-dead donor. Ann Surg 234:732-740

25. Murugan R, Venkataraman R, Wahed AS, Elder M, Hergenroeder G, Carter $M$ et al (2008) Increased plasma interleukin- 6 in donors is associated with lower recipient hospital-free survival after cadaveric organ transplantation. Crit Care Med 36:1810-1816

26. Rebolledo R, Liu B, Akhtar MZ, Ottens PJ, Zhang JN, Ploeg RJ et al (2014) Prednisolone has a positive effect on the kidney but not on the liver of brain dead rats: a potencial role in complement activation. J Transl Med 12:111

27. Kotsch K, Ulrich F, Reutzel-Selke A, Pascher A, Faber W, Warnick P et al (2008) Methylprednisolone therapy in deceased donors reduces inflammation in the donor liver and improves outcome after liver transplantation: a prospective randomized controlled trial. Ann Surg 248:1042-1050

28. Auraen H, Mollnes TE, Bjortuft O, Bakkan PA, Geiran O, Kongerud J et al (2013) Multiorgan procurement increases systemic inflammation in brain dead donors. Clin Transplant 27:613-618

\section{Submit your next manuscript to BioMed Central and take full advantage of:}

- Convenient online submission

- Thorough peer review

- No space constraints or color figure charges

- Immediate publication on acceptance

- Inclusion in PubMed, CAS, Scopus and Google Scholar

- Research which is freely available for redistribution

Submit your manuscript at 